\title{
Assessment of contributing risk factors for premature menopause in Bangladesh: Cox proportional hazard model analysis
}

\author{
SABRINA AFROSE ${ }^{1, \text { A-F}}$, N.A.M. FAISAL AHMED ${ }^{1, \mathrm{~A}, \mathrm{E}}$, MOST. FARIDA KHATUN ${ }^{2, \mathrm{E}}$, MOHAMMAD ALI ${ }^{1, \text { A-F }}$ \\ ${ }^{1}$ Statistics Discipline, Khulna University, Bangladesh \\ ${ }^{2}$ Pharmacy Discipline, Khulna University, Bangladesh
}

A - Study Design, B - Data Collection, C - Statistical Analysis, D - Data Interpretation, E - Manuscript Preparation, F - Literature Search, G - Funds Collection

Summary Background. Premature menopause has received much attention due to the increased life expectancy of women. It is harmful for women's lives, and it brings changes in women's behaviour. No study has been carried out in Bangladesh concerning premature menopause based on a national survey.

Objectives. The aim of this study was to explore the scenario of premature menopause among Bangladeshi women and to identify the risk factors associated with premature menopause.

Material and methods. In this study, we considered secondary data from the Bangladesh Demographic and Health Survey (BDHS) 2014. Data was collected from 17,863 ever-married women within the reproductive age of 15-49 years using two-stage stratified cluster sampling. The BDHS report showed that a women could not experience menopause before the age of 30 years. Thus, we took into consideration 9,336 women 30 years of age and above. After deleting the missing values and usual observations, 8,885 samples were considered for our final analysis. The Log-rank test and Cox proportional hazard model were used for statistical analysis.

Results. The results showed that region, educational attainment, wealth index, employment status, marital status and contraceptive method use status were statistically significant risk factors for premature menopause in Bangladesh.

Conclusions. From the entire study, it was confirmed that there were several risk factors for premature menopause in Bangladesh.

Key words: premature menopause, Bangladesh, regression analysis.

Afrose S, Ahmed NF, Khatun MF, Ali M. Assessment of contributing risk factors for premature menopause in Bangladesh: Cox proportional hazard model analysis. Fam Med Prim Care Rev 2020; 22(3): 193-196, doi: https://doi.org/10.5114/fmpcr.2020.98240.

\section{Background}

Menopause is the permanent cessation of menstruation due to the loss of ovarian follicular activity, which is diagnosed when a woman has gone without period for a year [1, 2]. Naturally, it occurs in a woman's life between the age of 45 to 55 years [3]. During this period, the ovaries begin to decrease the production of the sex hormones oestrogen and progesterone, which is a normal part of aging $[1,4]$. When menopause occurs before the age of 40 years, it is referred to as premature menopause [5].

In the current era, premature menopause is a major concern for midlife women in South East Asia, including Bangladesh [6]. Most of the women are uneducated and have no consciousness about premature menopausal status [7]. In Bangladesh, 74.4 years was the approximate average lifespan of women, and the average age of natural menopause was 51.14 years [8,9]. Now-a-days, the study of premature menopause has received much attention due to the increased life expectancy of women [10].

Numerous epidemiological studies have showed that women who experience premature menopause have a higher risk of overall mortality, cardiovascular diseases, neurological diseases, psychiatric diseases, osteoporosis, etc. [11-16]. The age of menopause was associated with reproductive, demographic, socio-economic, lifestyle and cultural factors [17, 18]. To our best knowledge, there has been no study to determine the prevalence and associated risk factors of premature menopause in Bangladesh.

\section{Objectives}

The aim of the study was to explore the premature menopausal scenario among Bangladeshi women and to identify the risk factors associated with premature menopause.

\section{Material and methods}

Data

Data was extracted from the nationally representative Bangladesh Demographic and Health Survey (BDHS), which was conducted in 2014. The BDHS used two-stage stratified cluster sampling, and data was collected from 17,863 ever-married women within the reproductive age of 15-49 years. A detailed description of the survey design, questionnaires and related information can be found elsewhere [19]. The BDHS report showed that a women could not experience menopause before the age of 30 years [19]. For this reason, we took into consideration 9,336 women 30 years of age and above. After deleting the missing values and usual observations, 8,885 samples were considered for our final analysis.

\section{Outcome variable}

Menopausal status and the current age of the women were available in the BDHS, 2014 data.

We considered current age as a proximate measurement of lifetime for survival analysis, because there was no exact menopausal age in our data. A menopausal woman was considered as premature menopausal if her current age was at most 40 years.

\section{Independent variables}

In this study, we considered region, religion, place of residence, educational attainment, wealth index, employment status, marital status, BMI and contraceptive method use status as independent variables. 


\section{Statistical analysis}

The Log-rank test was used to assess the association between premature menopausal status and independent variables. The Cox proportional hazard model was used to identify the significant risk factors associated with premature menopause. All analyses were carried out by SPSS 20.

\section{Ethical approval}

The BDHS data was approved by the Bangladesh medical research council, and informed consent was taken from the participants.

\section{Results}

The samples mean age in this study was $38.60 \pm 5.74$ years (ranging from 30 to 49 ). Approximately $4.80 \%$ of women had premature menopause. Table 1 illustrates the characteristics of the women. Table 2 representes the $p$-values obtained from the Log-rank test for assessing the association between premature menopausal status and selected explanatory variables. It was found that region, place of residence, educational attainment, wealth index, marital status and contraceptive method use status were significantly associated with premature menopausal status at $p<0.05$. The variables found significant were considered for the Cox proportional regression analysis. The hazard ratios and $p$-values obtained from the Cox proportional hazard model are presented in Table 3. The results showed that women who lived in the Khulna region had a 1.91 times higher chance to experience premature menopause compared to their counterparts. Table 3 depicts a 0.57 times lower chance of premature menopause among higher educated women compared to non-educated women. The analysis revealed that wealthy women had a 0.29 times lower chance to experience premature menopause compared to poor women. It was found that employed women were 1.24 times more likely to experience premature menopause than unemployed women. A woman who was widowed/divorced/separated had a 0.54 times lower chance to experience premature menopause than married women. Table 3 shows that women who used a contraceptive method had a 0.29 times lower chance to experience premature menopause than their counterparts.

\begin{tabular}{|c|c|c|c|}
\hline Variables & Categories & $n$ & $\%$ \\
\hline \multirow[t]{7}{*}{ Region } & Barisal & 1,069 & 12.0 \\
\hline & Chittagong & 1,329 & 15.0 \\
\hline & Dhaka & 1,483 & 16.7 \\
\hline & Khulna & 1,385 & 15.6 \\
\hline & Rajshahi & 1,336 & 15.0 \\
\hline & Rangpur & 1,266 & 14.2 \\
\hline & Sylhet & 1,017 & 11.4 \\
\hline \multirow[t]{2}{*}{ Place of residence } & urban & 3,129 & 35.2 \\
\hline & rural & 5,756 & 64.8 \\
\hline \multirow{4}{*}{$\begin{array}{l}\text { Educational attain- } \\
\text { ment }\end{array}$} & no education & 3,250 & 36.6 \\
\hline & primary & 2,774 & 31.2 \\
\hline & secondary & 2,199 & 24.7 \\
\hline & higher & 662 & 7.5 \\
\hline \multirow[t]{3}{*}{ Wealth index } & poor & 3,247 & 36.5 \\
\hline & middle & 1,785 & 20.1 \\
\hline & wealthy & 3,853 & 43.4 \\
\hline
\end{tabular}

\begin{tabular}{|l|l|l|l|}
\hline \multirow{2}{*}{ Employment status } & unemployed & 5,539 & 62.3 \\
\cline { 2 - 4 } & employed & 3,346 & 37.7 \\
\hline \multirow{3}{*}{ Marital status } & married & 8,088 & 91.0 \\
\cline { 2 - 4 } & $\begin{array}{l}\text { widowed/divorced/ } \\
\text { /separated }\end{array}$ & 797 & 9.0 \\
\hline \multirow{2}{*}{$\begin{array}{l}\text { Contraceptive } \\
\text { method use status }\end{array}$} & no & 3,555 & 40.0 \\
\cline { 2 - 4 } & yes & 5,330 & 60.0 \\
\hline \multirow{3}{*}{ BMI } & under weight & 1,450 & 16.3 \\
\cline { 2 - 4 } & healthy weight & 4,792 & 53.9 \\
\cline { 2 - 4 } & over weight & 2,095 & 23.6 \\
\cline { 2 - 4 } & obese & 5,48 & 6.2 \\
\hline
\end{tabular}

Table 2. $p$-values obtained from the Log-rank test for premature menopausal status with the selected explanatory variables

\begin{tabular}{|l|l|}
\hline Variables & Log-rank test $p$ \\
\hline
\end{tabular}

\begin{tabular}{|l|l|}
\hline Region & $0.01^{*}$ \\
\hline Place of residence & $<0.001^{*}$ \\
\hline Educational attainment & $0.01^{*}$ \\
\hline Wealth index & $<0.001^{*}$ \\
\hline Working status & $0.01^{*}$ \\
\hline Marital status & $0.01^{*}$ \\
\hline Contraceptive method use status & $0.04^{*}$ \\
\hline BMI & 0.32 \\
\hline
\end{tabular}

* Indicates a significance at $5 \%$.

Table 3. Hazard ratios and $p$-values obtained from the Cox proportional hazard analysis for premature menopause

\begin{tabular}{|c|c|c|c|c|}
\hline \multirow[t]{2}{*}{ Factors } & \multirow[t]{2}{*}{$p$} & \multirow[t]{2}{*}{ HR } & \multicolumn{2}{|c|}{$95 \%$ C.I. for $\operatorname{EXP}(B)$} \\
\hline & & & lower & upper \\
\hline $\begin{array}{l}\text { Region } \\
\text { Barisal (ref) } \\
\text { Chittagong } \\
\text { Dhaka } \\
\text { Khulna } \\
\text { Rajshahi } \\
\text { Rangpur } \\
\text { Sylhet } \\
\end{array}$ & \begin{tabular}{|l|}
0.32 \\
0.41 \\
$<0.001 *$ \\
0.19 \\
0.10 \\
0.76 \\
\end{tabular} & $\begin{array}{l}1 \\
1.22 \\
1.18 \\
1.91 \\
1.29 \\
1.38 \\
0.93 \\
\end{array}$ & \begin{tabular}{|l|}
0.82 \\
0.79 \\
1.33 \\
0.88 \\
0.94 \\
0.59 \\
\end{tabular} & $\begin{array}{l}1.83 \\
1.76 \\
2.74 \\
1.91 \\
2.03 \\
1.46 \\
\end{array}$ \\
\hline $\begin{array}{l}\text { Place of Residence } \\
\text { urban (ref) } \\
\text { rural }\end{array}$ & 0.12 & $\begin{array}{l}1 \\
1.20 \\
\end{array}$ & 0.95 & 1.52 \\
\hline $\begin{array}{l}\text { Educational attain- } \\
\text { ment } \\
\text { no education (ref) } \\
\text { primary } \\
\text { secondary } \\
\text { higher }\end{array}$ & \begin{tabular}{|l|}
0.73 \\
0.53 \\
$\mathbf{0 . 0 1} *$ \\
\end{tabular} & $\begin{array}{l}1 \\
1.04 \\
1.09 \\
\mathbf{0 . 4 3}\end{array}$ & \begin{tabular}{|l|}
0.83 \\
0.83 \\
$\mathbf{0 . 2 2}$ \\
\end{tabular} & $\begin{array}{l}1.31 \\
1.43 \\
0.83 \\
\end{array}$ \\
\hline $\begin{array}{l}\text { Wealth index } \\
\text { poor (ref) } \\
\text { middle } \\
\text { wealthy } \\
\end{array}$ & \begin{tabular}{|l|}
0.55 \\
$\mathbf{0 . 0 1} *$ \\
\end{tabular} & $\begin{array}{l}1 \\
0.93 \\
\mathbf{0 . 7 2} \\
\end{array}$ & \begin{tabular}{|l|}
0.72 \\
0.55 \\
\end{tabular} & $\begin{array}{l}1.19 \\
0.93 \\
\end{array}$ \\
\hline $\begin{array}{l}\text { Employment status } \\
\text { unemployed (ref) } \\
\text { employed }\end{array}$ & $0.04 *$ & $\begin{array}{l}1 \\
1.24\end{array}$ & 1.02 & 1.50 \\
\hline $\begin{array}{l}\text { Marital status } \\
\text { married (ref) } \\
\text { widowed/di- } \\
\text { vorced/separated }\end{array}$ & $<0.001 *$ & $\begin{array}{l}1 \\
0.46\end{array}$ & 0.30 & 0.69 \\
\hline $\begin{array}{l}\text { Contraceptive } \\
\text { method use status } \\
\text { no (ref) } \\
\text { yes }\end{array}$ & $0.01 *$ & $\begin{array}{l}1 \\
0.71\end{array}$ & 0.59 & 0.87 \\
\hline
\end{tabular}

$*$ Indicates a significance at $5 \%$. 


\section{Discussion}

The present study was conducted based on BDHS data and found that approximately $4.80 \%$ of women had experienced premature menopause, which was higher than similar previous studies $[14,18]$. The results showed that women who lived in the Khulna region had a higher chance to experience premature menopause compared to other regions. Khulna is one of the coastal regions in Bangladesh, and people are adversely affected by salinity problems [20]. A study on the Khulna region showed that women's health status was adversely affected by drinking saline water [21]. This may be the cause for this findings. Policy makers should focus on the factors responsible for the highest rate of premature menopause in the Khulna region.

The results showed that educational attainment and wealth index were significantly associated with premature menopause. The results indicated that highly educated and wealthy women had less chance to experience premature menopause. These findings were similar to previous studies $[22,23]$. Highly educated and wealthy women are more conscious about their health, and they have knowledge about the consequences of premature menopause [24]. This may be the cause for these findings.

The results also showed that employed women had a higher chance to experience premature menopause. Even now, in Bangladesh, employed women face several difficulties in their workplace that could be a contributing factor for premature menopause [25]. This may be the cause for these finding. We found that a woman's contraceptive method was associated with premature menopausal status. The findings were consistent with a prior prospective [26].
Married women had a higher chance of premature menopause than women who were widowed/divorced/separated, which was contradicted by the results of a former study conducted in United States [27, 28]. This could be due to sociocultural variations.

\section{Limitations of the study}

This study has certain limitations. There is no exact age of menopause. We considered the current age of the women as a proximity measurement of menopausal age. Since this is a cross-sectional study, it is difficult to establish a causal relationship between premature menopause and selected independent variables, whereas a longitudinal study is more effective. Despite the above limitations, the findings of this study will contribute to understanding and identifying the associated risk factors of premature menopause in Bangladesh.

\section{Conclusions}

The study was conducted based on nationally represented data, and the findings revealed that region, educational attainment, wealth index, employment status, marital status and contraceptive method use status were significant risk factors for premature menopause in Bangladesh. Governments should take the necessary steps to enhance public awareness about the causes and consequences of premature menopause.

Acknowledgements. The authors would like to thank the authorities of the BDHS for granting permission to use their dataset in this research.

Source of funding: This work was funded from the authors' own resources.

Conflicts of interest: The authors declare no conflicts of interest.

\section{References}

1. World Health Organization. Research on the menopause in the 1990's: a report of the WHO Scientific Group. Geneva: WHO; 1996

2. Weismiller DG. The perimenopause and menopause experience: an overview. Clin Fam Pract 2002; 4(1): 1-12, doi: 10.1016/S15225720(03)00047-3.

3. NHS. Overview menopause. Available from URL: https://www.nhs.uk/conditions/menopause/.

4. Utian WH. Semantics, menopause-related terminology, and the STRAW reproductive aging staging system. Menopause 2001; 8(6): 398-401.

5. Shuster LT, Rhodes DJ, Gostout BS, et al. Premature menopause or early menopause: long-term health consequences. Maturitas 2010; 65(2): 161-166.

6. Hachul H, Polesel DN, Nozoe KT, et al. The age of menopause and their associated factors: a cross-sectional population-based study. $J$ Women's Health Care 2016; 5(5): 1-10.

7. Ahmed K, Jahan P, Nadia I, et al., Assessment of menopausal symptoms among early and late menopausal midlife Bangladeshi women and their impact on the quality of life. J Menopausal Med 2016; 22(1): 39-46.

8. World Health Organization. Life expectancy increased by 5 years since 2000, but health inequalities persist. Geneva: World Health Statistics; 2016.

9. Rahman S, Salehin F, Iqbal A. Menopausal symptoms assessment among middle age women in Kushtia, Bangladesh. BMC Research Notes 2011; 4(1): 188

10. Natarajan J, Vidya S, Mulira RS. Review literature on distress during the menopausal transition and their impact on the quality of life of women: what is the evidence. IOSR-JNHS 2013; 2: 1-10.

11. Chen MH, SU TP, Li CT, et al. Symptomatic menopausal transition increases the risk of new-onset depressive disorder in later life: a nationwide prospective cohort study in Taiwan. PloS ONE 2013; 8(3): e59899, doi: 10.1371/journal.pone.0059899.

12. Carr MC. The emergence of the metabolic syndrome with menopause. J Clin Endocrinol Metab 2003; 88(6): 2404-2411.

13. Do KA, Green A, Guthrie JR, et al. Longitudinal study of risk factors for coronary heart disease across the menopausal transition. Am $J$ Epidemiol 2000; 151(6): 584-593.

14. Okeke TC, Anyaehie UB, Ezenyeaku CC. Premature menopause. Ann Med Health Sci Res 2013; 3(1): 90-95.

15. Abdullah B, Moize B, Ismailet BA, al. Prevalence of menopausal symptoms, its effect to quality of life among Malaysian women and their treatment seeking behaviour. Med J Malaysia 2017; 72(2): 94-99.

16. Zhu D, Chung HF, Dobson AJ, et al, Age at natural menopause and risk of incident cardiovascular disease: a pooled analysis of individual patient data. Lancet Public Health 2019; 4(11): e553-e564.

17. Carlson KJ. Outcomes of hysterectomy. Clin Obstet Gynecol 1997; 40(4): 939-946.

18. Gharaibeh AM, Al-Bdour AE-NE, Akasheh HF. Premature and early menopause: risk factors in Jordanian women. JRMS 2010; 102(352): $1-5$.

19. NIPORT. Bangladesh Demographic and Health Survey 2014. Dhaka (Bangladesh), Rockville (MD, USA): NIPORT, Mitra and Associates, ICF International; 2016.

20. Alam MZ, Carpenter-Boggs L, Shishir M, et al. Effect of salinity intrusion on food crops, livestock, and fish species at Kalapara Coastal Belt in Bangladesh. J Food Quality 2017; 5: 1-23. 
21. Shohel T, Hossain T, Adhikary N, et al. Effects of water salinity on degrading health status of the women in south-western rural Bangladesh. JSERD 2010; 8(6): 1136-1142.

22. Al-Sejari MM. Age at natural menopause and menopausal symptoms among Saudi Arabian women in Al-Khobar. Columbus: The Ohio State University; 2005.

23. Benjamin $\mathrm{F}$. The age of the menarche and of the menopause in white South African women and certain factors influencing these times. S Afr Med J 1960; 34(4): 316-320.

24. Sharpe TT, Harrison KM, Dean HD. Summary of CDC consultation to address social determinants of health for prevention of disparities in HIV/AIDS, viral hepatitis, sexually transmitted diseases, and tuberculosis. Public Health Rep 2010; 125(4 Suppl.): 11-15.

25. Islam T, Pal JK. Conflicts and challenges faced by employed women in family life: a study on Sylhet city. 2016. East West Journal of Business and Social Studies 2016; 5: 1-14.

26. Park YJ, Kim HS, Kang HC. The age at menopause and related factors in Korean women. J Korean Acad Nurs 2002; 32(7): 1024-1031.

27. Nelson LM, Covington SN, Rebar RW. An update: spontaneous premature ovarian failure is not an early menopause. Fertil Steril 2005; 83(5): 1327-1332.

28. Stepaniak U, Szafraniec K, Kubinova R, et al. Age at natural menopause in three central and eastern European urban populations: the HAPIEE study. Maturitas 2013; 75(1): 87-93.

\section{Tables: 3}

Figures: 0

References: 28

Received: 19.10 .2019

Reviewed: 18.11.2019

Accepted: 11.05.2020

Address for correspondence:

Mohammad Ali, MSc

Statistics Discipline

Khulna University

Khulna-9208

Bangladesh

Tel.: +880 1745077767

E-mail: ail.ru.stat@gmail.com 